\title{
Studies on the Pathogenesis of Type I (Distal) Renal Tubular Acidosis as Revealed by the Urinary $\mathrm{PCO}_{2}$ Tensions
}

\author{
M. L. Halperin, M. B. Goldstein, A. Haig, M. D. Johnson, and B. J. Stinebaugh \\ From the Renal Departments, St. Michael's Hospital, University of Toronto, \\ Toronto, Canada and Gorgas Hospital, Balboa Heights, Canal Zone, Panama
}

A в S T R A C T This study was designed to investigate the pathogenesis of type I (distal) renal tubular acidosis.

Urinary and blood $\mathrm{PCO}_{2}$ tensions were determined when the $\mathrm{pH}$ of the urine was equal to or exceeded the corresponding blood $\mathrm{pH}$. This provided an indication of net hydrogen ion secretion in the distal nephron. In 16 normal subjects, the $\mathrm{PCO}_{2}$ of the urine exceeded blood values (U-B $\mathrm{PCO}_{2}$ ) by $32.7 \pm 3.1 \mathrm{~mm} \mathrm{Hg}$. In contrast, the urinary $\mathrm{PCO}_{2}$ tensions in 10 patients with type I (distal) renal tubular acidosis were not significantly greater than blood values (U-B $\mathrm{PCO}_{2}=2.0 \pm 2.2 \mathrm{~mm}$ $\mathrm{Hg}$ ). These results indicate that type I (distal) renal tubular acidosis is caused by failure of the cells of the distal nephron to secrete hydrogen ions rather than to gradient-limited hydrogen ion addition to the urine. This is suggested by the fact that urinary $\mathrm{Pcos}_{\mathrm{c}}$ levels should be higher than blood $\mathrm{PCO}_{2}$ levels when hydrogen ions are secreted into urine containing bicarbonate in the distal nephron and they were not in this study despite the presence of a favorable hydrogen ion gradient (tubular fluid $\mathrm{pH}$ exceeded blood $\mathrm{pH}$ ).

\section{INTRODUCTION}

Renal tubular acidosis is a clinical syndrome characterized by a sustained metabolic acidosis in which there is a low concentration of serum bicarbonate and an approximately commensurate elevation in serum chloride. This syndrome has been regarded as a consequence of an inability to excrete the normal dietary acid load in the urine. Renal tubular acidosis can be subdivided into two major classes. In the proximal type (II), bicarbonate reabsorption is significantly reduced causing aci-

This work was presented at the Meeting of the Canadian Society of Clinical Investigation, Edmonton, Alberta, Canada, January 1973 (1), and to the National Meeting of the American Federation for Clinical Research in Atlantic City, N. J., May 1973 (2).

Received for publication 8 March 1973 and in revised form 27 August 1973. dosis with a urine $\mathrm{pH}$ that is inappropriately high. When the bicarbonate concentration falls below the tubular threshold, bicarbonaturia will disappear and urine $\mathrm{pH}$ decreases to normal minimum values, suggesting that the acidification process of the distal nephron is intact (for reviews see references $3-6$ ).

Classical (type I or distal) renal tubular acidosis is characterized by metabolic acidosis secondary to an inability of the cells of the distal nephron to produce a sufficient hydrogen ion gradient between blood and urine regardless of the degree of systemic acidosis (7). The defect could be: $(a)$ an increased rate of hydrogen ion back diffusion from the urine despite a normal distal nephron hydrogen ion secretory rate; $(b)$ normal secretory capacity of the distal nephron but an inability to secrete hydrogen ions against a significant hydrogen ion gradient; or $(c)$ localized destruction and/or dysfunction of the distal nephron cells that secrete hydrogen ions. Unlike proximal renal tubular acidosis, bicarbonate excretion in this type of renal tubular acidosis is less than $15 \%$ of the tubular maximum.

Urinary $\mathrm{PCO}_{2}$ levels can be used to evaluate hydrogen ion secretion in the distal nephron (collecting duct) providing the following minimum criteria are met: $(a)$ Bicarbonate must be present in sufficient quantity in the urine at this site (urine $\mathrm{pH}$ in these studies was greater than 7.4). (b) Carbonic anhydrase must be absent from the luminal surface in the distal nephron causing delayed dehydration of $\mathrm{H}_{2} \mathrm{CO}_{3}(8-10)$. (c) The lower urinary tract must be relatively impermeable to carbon dioxide formed in this way. There are numerous reports in the literature to support these criteria (8-12). Therefore urinary $\mathrm{PCO}_{2}$ levels could provide a qualitative index for collecting duct hydrogen-ion secretion.

In our studies, we measured the urinary $\mathrm{Pco}_{2}$ levels in patients with type I (distal) renal tubular acidosis and in normal subjects. Results to be presented indicate that type I (distal) renal tubular acidosis is most likely caused by destruction and/or dysfunction of the cells of the distal nephron that secrete hydrogen ions against a 
TABLE I

Clinical and Biochemical Information on 10 Patients with Type I (Distal) Renal Tubular Acidosis

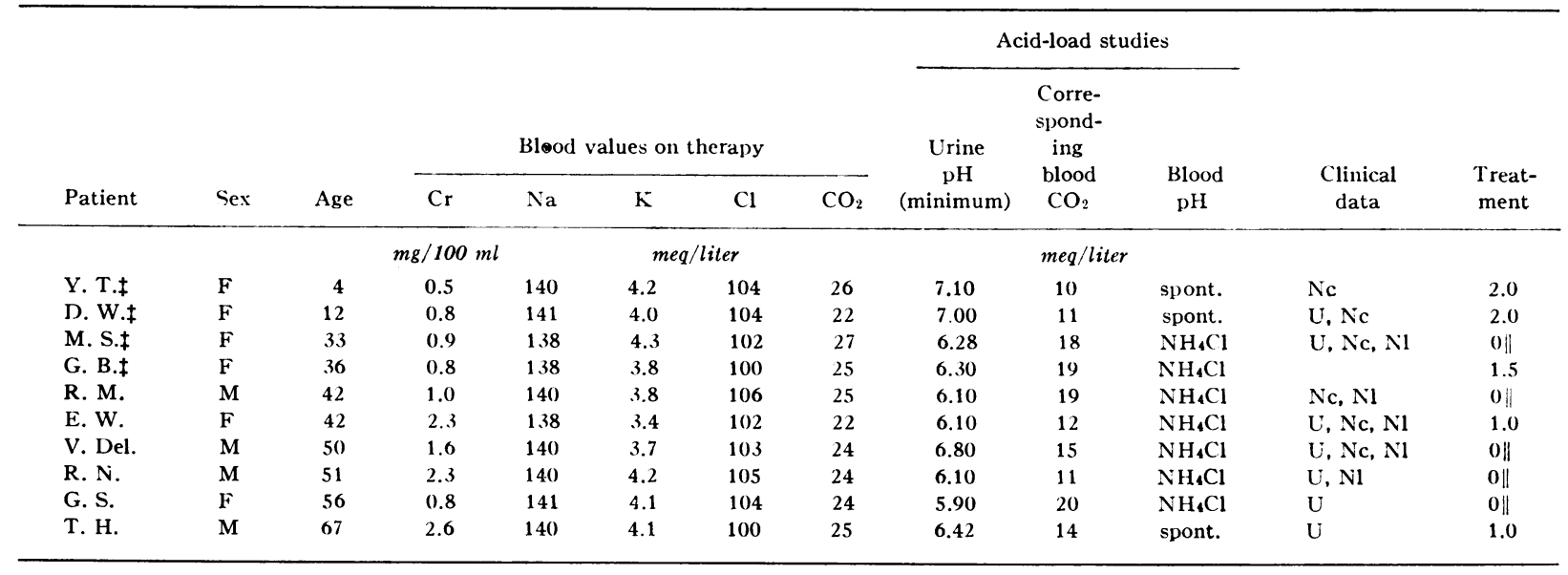

$* \mathrm{NaHCO}_{3}$ to correct acidosis (mlliequivalents per kilogram per day).

$\ddagger$ These patients were studied in detail and reported in Table $\mathrm{V}$.

$\$$ Spont. = spontaneous; $\mathrm{Nc}=$ nephrocalcinos; $\mathrm{U}=$ history of urinary tract infection: $\mathrm{NH} \mathrm{H}_{4} \mathrm{Cl}=$ ammonium chloride load $(7) ; \mathrm{Nl}=$ nephrolithiasis.

II Incomplete renal tubular acidosis.

steep gradient rather than to either an increased back diffusion of hydrogen ions in the presence of a normal hydrogen ion secretory rate or gradient-limited hydrogen ion secretion (gradient-type lesions). This conclusion was drawn from the fact that urine minus blood $\mathrm{PCO}_{2}\left(\mathrm{U}-\mathrm{B} \mathrm{PCO}_{2}\right)^{1}$ levels were increased in normal subjects when given a sodium bicarbonate load, but they were not elevated in patients with type I (distal) renal tubular acidosis under conditions when no secretory gradients for hydrogen ion existed.

\section{METHODS}

Subjects. 10 unrelated patients (ages 4-67 yr) with type I (distal) renal tubular acidosis and 16 normal subjects (ages 21-64 yr) were studied. For purposes of clarity, the patients with renal tubular acidosis are identified by their initials. Most of these patients had either medullary nephrocalcinosis or nephrolithiasis. There was no history of nephrotoxic drug exposure, obstructive uropathy, or dysproteinemia. Most patients had a history of urinary tract infections in the past, but none were actively infected at the time of this study. In each case of type I (distal) renal tubular acidosis, the diagnosis was established by the $\mathrm{NH}_{4} \mathrm{Cl}$-loading test of Wrong and Davies (6). The minimum urine $\mathrm{pH}$ achieved in these patients was greater than 5.9 despite the induced systemic metabolic acidosis. This diagnosis was supported by the fact that the serum bicarbonate could be maintained within normal limits by 2.0 $\mathrm{meq} / \mathrm{kg} / \mathrm{day}$ or less of sodium bicarbonate. Pertinent clinical data are presented in Table I.

The normal subjects all achieved a urine $\mathrm{pH}$ of 5.35 or less on the second voided fasting a.m. urine or on the $\mathrm{NH}_{4} \mathrm{Cl}$-loading test (7). All subjects had normal serum potassium levels and were free of obvious disease.

${ }^{1}$ Abbreviation used in this paper: U-B $\mathrm{PCO}_{2}$, urine minus blood $\mathrm{PCO}_{2}$.

\section{Procedures}

General. 26 subjects were investigated. All studies were initiated in the morning (9:00 a.m.) with breakfast withheld. There were at least two sets of observations on each subject. A urinalysis, urine $\mathrm{pH}, \mathrm{PCO}_{2}$ and $\mathrm{CO}_{2}$ content, serum sodium, potassium, chloride, $\mathrm{CO}_{2}$ content, and creatinine of blood urea nitrogen (BUN) were done before the study. Acidification and bicarbonate-loading studies were done on separate days. An oral sodium bicarbonate load of $0.5-2.0 \mathrm{meq} / \mathrm{kg}$ body weight with $500 \mathrm{~cm}^{3}$ of water was then taken on the morning of study by each subject. The dose of sodium bicarbonate was adjusted so that the urine $\mathrm{pH}$ would be greater than the corresponding blood $\mathrm{pH}$. A second voided urine, and blood samples were analyzed as above. Urine samples were accepted only if the $\mathrm{pH}$ of the preceding sample was greater than 7.0 to minimize $\mathrm{CO}_{2}$ production from mixing of alkaline and acid urines in the bladder. In three subjects the sodium bicarbonate was also administered intravenously in a separate study.

All urine samples were aspirated into a sealed syringe and kept anaerobic for $\mathrm{pH}, \mathrm{PCO}_{2}$, and $\mathrm{CO}_{2}$ content determinations immediately after collection. Values that did not agree when applied to the Henderson-Hasselbalch equation were reanalyzed or discarded. The samples were retained at $0-4^{\circ} \mathrm{C}$ for this purpose.

Blood sampling. In patients with type I (distal) renal tubular acidosis, an arterial blood sample was utilized to provide a minimum estimate of the renal medullary $\mathrm{PCO}_{2}$. In normal subjects, all blood determinations were done on venous blood, as the magnitude of the U-B $\mathrm{PCO}_{2}$ gradient removed the necessity to obtain the minimum estimate of renal medullary $\mathrm{PCO}_{2}$. Before obtaining the sample from the antecubital vein, the subject remained recumbent for at least $10 \mathrm{~min}$. The blood sample was obtained without the use of a tourniquet and forearm muscular contraction was avoided as much as possible.

Urine sampling. In a pilot study we demonstrated that there was no significant difference in the urine $\mathrm{PCO}_{2}$ be- 
TABLE II

Urine and Blood Measurements in Normal Subjects with Bicarbonate Loading

\begin{tabular}{|c|c|c|c|c|c|c|c|c|c|c|c|}
\hline \multirow[b]{2}{*}{ Patient } & \multirow[b]{2}{*}{ Sex } & \multirow{2}{*}{$\begin{array}{c}\text { Minimum } \\
\text { urine } \mathrm{pH} \\
\text { before } \\
\text { bicarbonate }\end{array}$} & \multicolumn{6}{|c|}{ Blood } & \multicolumn{2}{|c|}{ Urine } & \multirow{2}{*}{$\begin{array}{c}\mathrm{U}-\mathrm{B} \\
\mathrm{PCO} 2\end{array}$} \\
\hline & & & $\mathrm{Nq}$ & $\mathbf{K}$ & $\mathrm{Cl}$ & $\mathrm{CO}_{2}$ & $\mathrm{pH}$ & Pco: & $\mathrm{pH}$ & $\mathrm{PcO}_{2}$ & \\
\hline & & & & \multicolumn{3}{|c|}{ meq/liter } & & $m m \mathrm{Hg}$ & & $m m \mathrm{Hg}$ & $m m \mathrm{Hg}$ \\
\hline J. C. & $\mathbf{M}$ & 4.95 & 140 & 4.0 & 104 & 24 & 7.36 & 44 & 7.70 & 85 & 41 \\
\hline M. H. & $\mathbf{M}$ & 5.26 & 145 & 4.0 & 103 & 30 & 7.45 & 45 & 7.50 & 103 & 58 \\
\hline M. J. & M & 5.20 & 144 & 3.7 & 102 & 30 & 7.45 & 48 & 8.10 & 87 & 39 \\
\hline A. L. & M & 5.30 & 141 & 3.8 & 99 & 30 & 7.45 & 43 & 7.75 & 72 & 29 \\
\hline J. S. & $\mathbf{M}$ & 4.90 & 142 & 3.6 & 100 & 27 & 7.40 & 38 & 7.90 & 72 & 34 \\
\hline R. L. & $\mathrm{M}$ & 5.10 & 145 & 3.9 & 104 & 26 & 7.39 & 39 & 7.45 & 72 & 33 \\
\hline L. F. & $\mathbf{M}$ & 5.30 & 138 & 4.4 & 102 & 25 & 7.39 & 40 & 7.40 & 74 & 34 \\
\hline F. F. & M & 5.15 & 139 & 4.0 & 102 & 24 & 7.37 & 43 & 7.68 & 70 & 27 \\
\hline P. L. & M & 5.30 & 139 & 4.2 & 103 & 29 & 7.40 & 47 & 7.40 & 72 & 25 \\
\hline D. K. & $\mathbf{M}$ & 5.20 & 144 & 4.1 & 104 & 30 & 7.40 & 47 & 7.80 & 111 & 64 \\
\hline G. S. & $\mathbf{M}$ & 5.00 & 140 & 4.0 & 102 & 29 & 7.38 & 47 & 7.90 & 89 & 42 \\
\hline M. W. & $\mathrm{F}$ & 5.10 & 139 & 4.0 & 100 & 25 & 7.40 & 38 & 7.60 & 70 & 32 \\
\hline S. S. & $\mathrm{F}$ & 5.30 & 142 & 4.6 & 103 & 26 & 7.38 & 42 & 7.40 & 65 & 23 \\
\hline J. C. & $\mathrm{F}$ & 5.30 & 146 & 3.7 & 105 & 26 & 7.35 & 50 & 7.72 & 78 & 28 \\
\hline R. G. & $\mathrm{F}$ & 4.90 & 141 & 3.8 & 101 & 25 & 7.35 & 50 & 7.90 & 69 & 19 \\
\hline M. O. & $\mathrm{F}$ & 5.20 & 141 & 3.8 & 100 & 29 & 7.36 & 54 & 7.60 & 84 & 30 \\
\hline
\end{tabular}

Minimum urine $\mathrm{pH}$ was achieved on spontaneously voided a.m. specimens in 13 subjects. $\mathrm{An} \mathrm{NH}_{4} \mathrm{Cl}$ load (7) was required in three subjects to achieve a urine $\mathrm{pH}$ of less than 5.30. All subjects received $0.5-2.0$ meq $\mathrm{NaHCO}_{3} / \mathrm{kg}$ body wt. The urine $\mathrm{pH}$ exceeded the venous blood $\mathrm{pH}$ in each study.

tween freshly voided urine under oil and that allowed to stand up to $5 \mathrm{~min}$ in the collection vessel without oil $\left(\Delta \mathrm{PcO}_{2}=0.8 \pm 0.026 \mathrm{~mm} \mathrm{Hg}, n=5\right)$. Therefore urine specimens were not collected under oil in all cases. To evaluate the necessity of an indwelling catheter, the following study was done. 15 patients with indwelling catheters had the catheter clamped for $1 \mathrm{~h}$. After anaerobic collection of a portion of bladder urine the remainder was allowed to flow freely into the collection vessel. The $\mathrm{PCO}_{2}$ was higher in the specimens obtained anaerobically, but the magnitude of this difference was small $(5 \pm 2.2 \%$ of control). As this represents a change of $\mathrm{PCO}_{2}$ of only $2-4 \mathrm{~mm}$ $\mathrm{Hg}$, we did not catheterize the majority of the subjects studied.

Since patients with chronic renal insufficiency of various causes have demonstrated an impaired ability to elevate their urinary $\mathrm{PCO}_{2}(13,14)$, only those patients with normal serum creatinines were selected for more detailed studies. To ensure that the tubular fluid $\mathrm{pH}$ was greater than blood $\mathrm{pH}$, a larger dose of sodium bicarbonate $(4 \mathrm{meq} / \mathrm{kg}$ body weight) was given for 2 days before the study and repeated as an acute load at the beginning of the study in subjects M. S. and G. B. One patient (Y. T.) was studied by the intravenous infusion of sodium bicarbonate $1 \mathrm{meq} /$ min instead of oral ingestion. Arterial blood samples were drawn at the midpoint of the collection period and these patients were catheterized and urines were collected under oil. These studies are reported in Table IV.

\section{Laboratory methods}

Serum $\mathrm{Na}^{+}$and $\mathrm{K}^{+}$were measured on a Technicon AutoAnalyzer flame photometer with an internal lithium standard (Technicon Instruments Corp., Tarrytown, N. Y.).
Chloride was measured by the autoanalyzer method of Zall, Fisher, and Garner (15). Serum and urinary $\mathrm{CO}_{2}$ content were measured by the method described by Skeggs (16), adapted for use in the AutoAnalyzer. BUN and creatinine were determined by standard autoanalyzer methods. Phosphorus was measured by the method of Fiske and Subbarow (17). Blood $\mathrm{pH}$ and $\mathrm{PCO}_{2}$ and urinary $\mathrm{PCO}_{2}$ were anaerobically determined immediately at $38^{\circ} \mathrm{C}$ with an Instrumentation Laboratory model $313 \mathrm{pH}$ blood gas analyzer (Instrumentation Laboratory, Inc., Lexington, Mass.). Urinary $\mathrm{pH}$ was also determined immediately with a Radiometer $\mathrm{pH}$ meter, model $\mathrm{pH}$ M $22 \mathrm{Q}$ (Radiometer Co., Copenhagen, Denmark). These experimentally derived values were tested in the Henderson-Hasselbalch equation and only those values which were within a $10 \%$ variation were accepted.

The urinary buffer curves were determined by the back titration of $1-\mathrm{ml}$ portions of urine from $\mathrm{pH} 4.5$ to 8.5 with $0.133 \mathrm{~N} \mathrm{NaOH}$ after the removal of bicarbonate by acidification and aeration for $4 \mathrm{~h}$. The titrant was delivered in $0.02-\mathrm{ml}$ quantities by a Radiometer ABU12 AutoBurette into a Radiometer TTA31 microtitration assembly controlled by a Radiometer TTTlc automatic titrator. As the buffer curve was linear in all cases, the buffer capacity was determined by dividing the urine buffer concentration by the $\mathrm{pH}$ change.

\section{RESULTS}

Normal subjects. All normal subjects in this study achieved a urine $\mathrm{pH}$ which was equal to or greater than the $\mathrm{pH}$ of their venous blood after the ingestion of $0.5-2$ $\mathrm{meq} / \mathrm{kg}$ of sodium bicarbonate. At this time there was 
TABLE III

Urine and Blood Measurements during Acute Bicarbonate Loading in Patients with Type I (Distal) Renal Tubular Acidosis

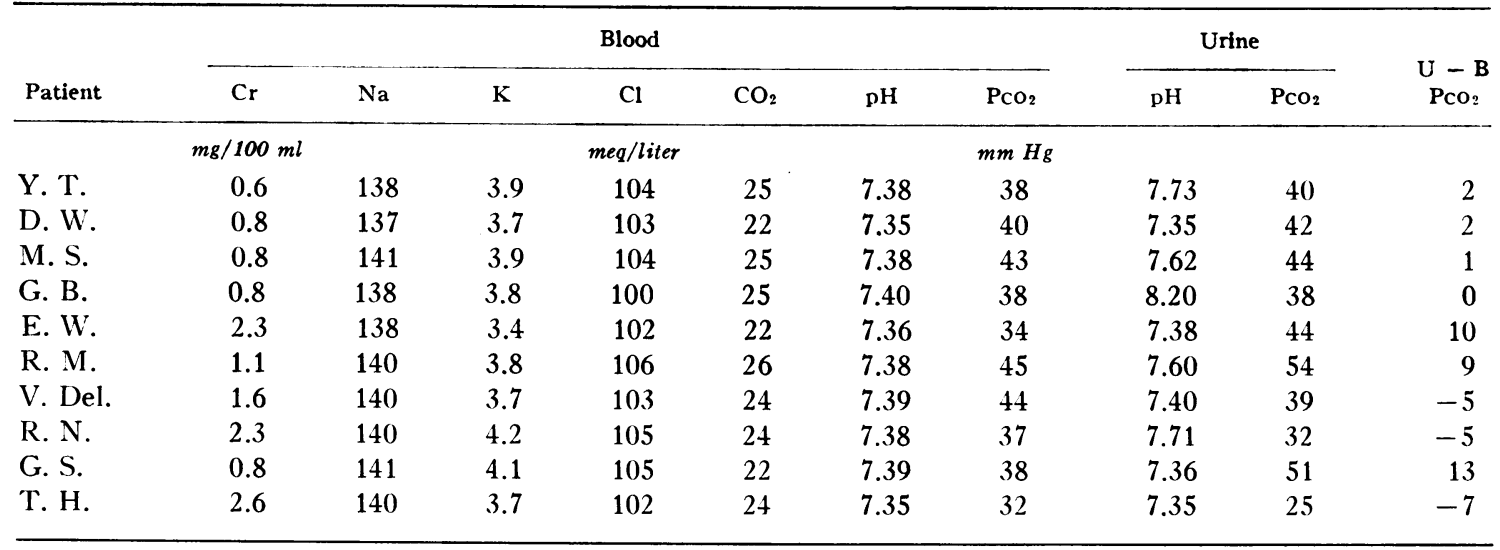

All subjects received $0.5-2.0 \mathrm{meq} / \mathrm{kg}$ of sodium bicarbonate. The blood values represent the midpoint in the collection period selected for presentation. Serial collection periods were performed in each patient. The period in which the urine $\mathrm{pH}$ equalled or exceeded blood $\mathrm{pH}$ is presented for each patient.

no significant change in their blood $\mathrm{Pco}_{2}$, but the urine $\mathrm{PCO}_{2}$ increased markedly. The U-B $\mathrm{PCO}_{2}$ was $32.7 \pm 3.1$ $\mathrm{mm} \mathrm{Hg}$. These data are presented in Table II.

Paticnts with type I (distal) renal tubular acidosis. When the urine $\mathrm{pH}$ was elevated to levels equal to or greater than blood $\mathrm{pH}$, the urinary $\mathrm{PcO}_{2}$ level did not rise appreciably. The $\mathrm{U}-\mathrm{B} \mathrm{PCO}_{2}$ was $2.0 \pm 2.2 \mathrm{~mm} \mathrm{Hg}$ in these subjects (Table III). All the values for the U-B $\mathrm{PCO}_{2}$ differences reported in Table III are maximumobserved values recorded for this parameter as several of the studies were repeated on separate occasions and on multiple samples. The U-B $\mathrm{PCO}_{2}$ difference is therefore significantly lower in patients with type I (distal) renal tubular acidosis than in normal subjects $(P<$ 0.001 ). If there was $\mathrm{CO}_{2}$ loss after the urine left the renal pelvis, this could have lowered the absolute U-B
$\mathrm{PCO}_{2}$ difference in this study. However, identical methods of collection were employed in both normal subjects and the patients with type I (distal) renal tubular acidosis, and therefore similar losses should have occurred in both groups. For this reason, the absolute magnitude of the U-B $\mathrm{PCO}_{2}$ difference between the two groups should not be affected. Our results confirm the observations of Pak Poy and Wrong (13) and establish conclusively that patients with type I (distal) renal tubular acidosis have an impaired capacity to elevate their urine $\mathrm{PCO}_{2}$ after bicarbonate ingestion.

To conclusively establish that the tubular fluid $\mathrm{pH}$ exceeded the blood $\mathrm{pH}$, four subjects with type I (distal) renal tubular acidosis and a normal serum creatinine were restudied. Small U-B $\mathrm{PCO}_{2}$ and $\mathrm{pH}$ differences could have been overlooked when venous blood and open

TABLE IV

Urine and Arterial Blood Determinations after Bicarbonate Loading in Four Patients with Type I (Distal) Renal Tubular Acidosis

\begin{tabular}{|c|c|c|c|c|c|c|c|c|c|c|c|c|c|}
\hline \multirow[b]{2}{*}{ Patient } & \multicolumn{7}{|c|}{ Arterial blood } & \multicolumn{6}{|c|}{ Urine } \\
\hline & $\mathrm{Na}$ & $\mathrm{K}$ & $\mathrm{CO}_{2}$ & $\mathrm{Cl}$ & $\mathrm{Cr}$ & $\mathrm{pH}$ & $\mathrm{PCO}_{2}$ & $\dot{\mathrm{V}}$ & $\mathrm{pH}$ & Pco. & $\mathrm{HCO}_{3}$ & $\mathrm{PO}_{4}$ & $\begin{array}{c}\text { Buffer } \\
\text { capacity }\end{array}$ \\
\hline & & \multicolumn{2}{|c|}{ meq/liter } & & $g / 100$ & & $m m H g$ & $\mathrm{ml} / \mathrm{min}$ & & $m m \mathrm{Hg}$ & $\mu m / \min$ & $\mu g / \min$ & $\begin{array}{c}m m o l \\
H^{+} / p H U\end{array}$ \\
\hline Y. T. & 140 & 4.0 & 28.0 & 102 & 0.5 & 7.45 & 38 & 2.2 & 8.05 & 34 & 206 & 242 & 6.38 \\
\hline M. S. & 138 & 4.2 & 30.2 & 100 & 0.8 & 7.44 & 42 & 2.75 & 8.08 & 43.5 & 336 & 248 & 7.04 \\
\hline G. B. & 138 & 3.7 & 25.5 & 100 & 0.8 & 7.45 & 35 & 1.46 & 8.07 & 34 & 141 & 250 & 12.3 \\
\hline D. W. & 136 & 3.7 & 23 & 102 & 0.8 & 7.36 & 40 & 7.5 & 7.38 & 36 & 165 & 300 & - \\
\hline
\end{tabular}

For details, see Table III. Arterial blood was obtained in all patients. The urine was collected under oil by catheterization in patients Y. T., M. S., and G. B. 
air voiding were employed (Table III). Therefore, these studies were repeated with larger doses of sodium bicarbonate, arterial blood sampling, and urinary catheterization. There was no significant elevation of the urinary $\mathrm{PCO}_{2}$ in these patients (Table IV) despite the demonstration of excretion rates of bicarbonate and phosphate which are associated with urinary $\mathrm{PCO}_{2}$ elevations in normal subjects $(13,18)$. The absence of a significant U-B $\mathrm{PCO}_{2}$ difference in these patients indicates that delayed dehydration did not occur and suggests that the collecting duct and final urine $\mathrm{pH}$ are identical. As the urine $\mathrm{pH}$ exceeded the blood $\mathrm{pH}$ by $0.60,0.62$, and $0.64 \mathrm{U}$ in three of these patients ( $\mathrm{Y}$. $\mathrm{T}$., M. S., and G. B.), it is readily evident that the diffusion gradient for hydrogen ion in the collecting duct was into rather than out of the tubular lumen. Calculations outlined in footnote 2 quantitate the degree of $\mathrm{CO}_{2}$ loss required to raise the $\mathrm{pH}$ of the collecting duct tubular fluid in these studies.

\section{DISCUSSION}

\section{Technical considerations in the urinary $\mathrm{PCO}_{2}$} methods

To avoid the problem of nonconstancy of blood $\mathrm{PCO}_{2}$, results in this study were expressed as $\mathrm{U}-\mathrm{B} \mathrm{PCO}_{2}$ as

${ }^{2}$ Hills and Reid (19) demonstrated that the urine $\mathrm{PCO}_{2}$ could decrease up to $15 \mathrm{~mm} \mathrm{Hg}$ in transit from the renal pelvis to the urinary bladder. Such a $\mathrm{CO}_{2}$ loss might obscure the presence of a disequilibrium $\mathrm{pH}$. This would raise the question that the collecting duct $\mathrm{pH}$ might be lower than both the urine and arterial blood $\mathrm{pH}$. To ensure a significant margin of error, let us assume that this $\mathrm{PCO}_{2}$ decrease could be threefold higher. By adding $45 \mathrm{~mm}$ $\mathrm{Hg}$ to the bladder urinary $\mathrm{PCO}_{2}$ values, we can obtain a value for the renal pelvis $\mathrm{PCO}_{2}$. Simultaneous solution of the following equations will provide a value for the renal pelvis urine $\mathrm{pH}$.

$$
\begin{aligned}
\mathrm{pH}_{\mathrm{RP}} & =6.1+\log \frac{\mathrm{HCO}_{3 \mathrm{RP}}}{0.03\left(\mathrm{PCO}_{2 \mathrm{U}}+45\right)} \\
\mathrm{HCO}_{3 \mathrm{RP}} & =\left(\mathrm{pH}_{\mathrm{U}}-\mathrm{pH}_{\mathrm{RP}}\right) \cdot \mathrm{BC}+\mathrm{HCO}_{3 \mathrm{U}}
\end{aligned}
$$

where $R P=$ renal pelvis; $U=$ urinary, and $B C=$ buffer capacity. Applying the data to patients Y. T., M. S., and G. B., the renal pelvis urine $\mathrm{pH}$ would be $7.69,7.75$, and 7.71 , respectively. The assumed $\mathrm{PCO}_{2}$ decrement of $45 \mathrm{~mm}$ $\mathrm{Hg}$ would have arisen from the delayed dehydration of 1.35 $\mathrm{mmol} \mathrm{H}_{2} \mathrm{CO}_{3}(45 \times 0.03)$. This would necessitate the release of $1.35 \mathrm{mmol}$ of $\mathrm{H}^{+}$from urinary buffers to react. with urinary bicarbonate. The magnitude of $\mathrm{pH}$ change is calculated from the buffer capacity measured in this urine (Table IV) and represents a $\mathrm{pH}$ change of $0.21,0.19$, and 0.11 , respectively. By subtraction, the calculated collecting duct $\mathrm{pH}$ would have been $7.46,7.55$, and 7.58i.e. still greater than the corresponding arterial $\mathrm{pH}$ values. As urinary $\mathrm{PCO}_{2}$ losses of this magnitude are extremely unlikely to occur, we can conclude with confidence that the collecting duct $\mathrm{pH}$ exceeded the arterial blood $\mathrm{pH}$ in these three cases.
TABLE V

Urine $\mathrm{PCO}_{2}$ Values during Bicarbonate Loading in Patients with Type I (Distal) Renal

\begin{tabular}{|c|c|c|c|}
\hline \multicolumn{3}{|c|}{ Bicarbonate-loading studies } & \multirow[b]{2}{*}{ Reference } \\
\hline Urine $\mathrm{pH}$ & Urine Pco: & U - B PcO2 & \\
\hline & $m m \mathrm{Hg}$ & $m m \mathrm{Hg}$ & \\
\hline 6.75 & $21-33$ & - & Fig. 54-3 (3) \\
\hline $7.0-7.4$ & 36.1 & 一 & Fig. 4 (6) \\
\hline 7.20 & 35.7 & 0 & L. C. S. (26) \\
\hline 7.18 & 39.1 & -1.2 & V. V. (21) \\
\hline 7.06 & 34 & -9 & Gw. B. (22) \\
\hline 8.05 & 30 & -16.8 & P. E. (23) \\
\hline 7.84 & 65.9 & 25.9 & F. B. (22) \\
\hline 7.87 & 40.6 & 0.7 & L. K. $(7,13)$ \\
\hline 6.78 & 28.2 & 一 & H. V. (23) \\
\hline 6.58 & 41 & - & D. H. (23) \\
\hline 6.88 & 28.3 & - & M. T. (23) \\
\hline 7.65 & 47.7 & 6.6 & (24) \\
\hline 6.95 & 32 & -12 & Case 2 (25) \\
\hline
\end{tabular}
Tubular Acidosis

Data was extracted from studies in the literature on subjects with renal tubular acidosis in whom the urinary $\mathrm{PCO}_{2}$ was either measured directly or could be calculated. These values represent mean values of several observations.

recommended by Portwood, Seldin, Rector, and Cade (18). If urines of acid and alkaline $\mathrm{pH}$. were to mix in the bladder, such as would occur when plasma acid-base conditions are changing, urine with a high $\mathrm{PCO}_{2}$ would result. Therefore, urines were collected every $30-60 \mathrm{~min}$ and the samples were rejected if the prior urine collection had an acid $\mathrm{pH}$. We obviously could not prevent the admixture of acid and alkaline urines formed in heterogeneous nephrons, however, if this were the basis for the high U-B $\mathrm{PcO}_{2}$ tension described, it would have applied only to normal subjects and not to patients with distal renal tubular acidosis.

\section{Urinary $\mathrm{PCO}_{2}$ levels in alkaline urine}

The $\mathrm{Pco}_{2}$ level in freshly voided alkaline urine is considerably greater than that of blood (26-34). This observation was confirmed in this report (Table II). The urinary $\mathrm{PCO}_{2}$ levels obtained under similar circumstances in patients with distal renal tubular acidosis are in marked contrast to those observed in normal subjects. Our results (Table III) confirm the findings of Pak Poy and Wrong (13) and clearly establish that there is a diminished capacity for patients with type I (distal) renal tubular acidosis to elevate the $\mathrm{Pco}_{2}$ level in alkaline urine. Similar observations in type I (distal) renal tubular acidosis were also present in the results of several other authors (Table V). This defect is present in patients with both overt and incomplete type I (distal) 
renal tubular acidosis (patients who maintain normal serum bicarbonate levels, but fail to lower urine $\mathrm{pH}$ appropriately after an $\mathrm{NH}_{4} \mathrm{Cl}$ challenge). To appreciate the significance of these findings with regard to the pathogenesis of this disease, we must consider the process by which the urinary $\mathrm{PCO}_{2}$ is elevated in normal subjects.

\section{Physiological of elevated urinary $\mathrm{PcO}_{2}$ levels in alkaline urine}

Delayed dehydration of $\mathrm{H}_{2} \mathrm{CO}$ s. Ochwadt and Pitts (35) performed the most conclusive experiments to support the concept that delayed dehydration of $\mathrm{H}_{2} \mathrm{CO}_{3}$ is the mechanism for the high urinary $\mathrm{PCO}_{2}$ tensions of alkaline urine. Intravenous infusion of carbonic anhydrase completely abolished the U-B $\mathrm{PCO}_{2}$ difference in alkaline urine. Since the final urine contained carbonic anhydrase activity, they inferred that the $\mathrm{H}_{2} \mathrm{CO}_{3}$ dehydration reaction was in equilibrium in this study. They concluded that disequilibrium in this reaction in the distal nephron was responsible for the elevated $\mathrm{PCO}_{2}$ tensions. Direct support for the theory that hydrogen ion secretion was responsible for $\mathrm{H}_{2} \mathrm{CO}_{3}$ formation was provided by Rector et al. (for reviews see references $10,36,37)$. The $\mathrm{pH}$ of the distal nephron urine was measured by two methods and averaged $0.85 \mathrm{pH}$ units lower when measured directly as compared with measurements with the equilibrium concentration of $\mathrm{H}_{2} \mathrm{CO}_{3}$ (quinhydrone $\mathrm{pH}$ electrode). They concluded, together with the data cited above, that the acid disequilibrium $\mathrm{pH}$ of the distal nephron provides strong support for the theory of hydrogen ion secretion and could be predicted by the delayed dehydration theory of Pitts and Lotspeich (28). The presence of a disequilibrium $\mathrm{pH}$ in alkaline tubular fluid was confirmed recently by Vieira and Malnic (39) employing antimony electrodes.

Mixing hypothesis. Kennedy, Orloff, and Berliner (30) have proposed that alkaline and acid urines delivered from heterogeneous nephrons are mixed in the collecting duct system, thereby forming $\mathrm{H}_{2} \mathrm{CO}_{3}$ and hence resulting in a high U-B $\mathrm{PCO}_{2}$ gradient. This "mixing hypothesis" required the presence of urinary buffer for proton donation from the acid $\mathrm{pH}$ urine. Kennedy, Eden, and Berliner (31) demonstrated that dehydration of $\mathrm{H}_{2} \mathrm{CO}_{3}$ was immeasurably rapid in the absence of nonbicarbonate buffer despite the absence of carbonic anhydrase. However, nonbicarbonate buffer is always present in the urine. Portwood et al. (18) have shown that very small amounts of buffer such as were present in their studies, will delay the dehydration of $\mathrm{H}_{2} \mathrm{CO}_{3}$ sufficiently to generate high U-B $\mathrm{PCO}_{2}$ gradients. These authors (18) concluded that "the excretion of buffer although influencing urine $\mathrm{CO}_{2}$ tension to some extent, has only a minor effect in the range of buffer excretion ordinarily encountered." In addition there is no difference in urinary buffer excretion when one compares normals and patients with distal renal tubular acidosis $(13,40)$.

Kennedy et al. (30) proposed two major inconsistencies with the theory of delayed dehydration of $\mathrm{H}_{2} \mathrm{CO}_{3}$. (a) Urine $\mathrm{PCO}_{2}$ tensions increased as the concentration of urinary buffer increased. This could still be explained by the delayed dehydration hypothesis as follows: increased nonbicarbonate buffer levels would be titrated to the lower, disequilibrium $\mathrm{pH}$ in the distal nephron (caused by $\mathrm{H}_{2} \mathrm{CO}_{3}$ accumulation). As $\mathrm{H}_{2} \mathrm{CO}_{3}$ is dehydrated nonenzymatically in the lower urinary system, urinary $\mathrm{pH}$ would tend to rise. The large reservoir of potential hydrogen ions in the nonbicarbonate buffers will now donate protons and titrate some of the bicarbonate present. This would cause an additional elevation of the urine $\mathrm{H}_{2} \mathrm{CO}_{3}$ and thereby increase the urinary $\mathrm{PCO}_{2}$ level. (b) They postulated that carbonic anhydrase inhibitors would abolish hydrogen ion secretion in the distal nephron and should minimize U-B $\mathrm{PCO}_{2}$ gradients. These agents did not do so. Moreover, micropuncture studies of the distal nephron have demonstrated that hydrogen ion secretion of the distal nephron is not decreased, but actually increased by these agents (38). Therefore this second major objection to the theory of delayed $\mathrm{H}_{2} \mathrm{CO}_{3}$ dehydration is also invalid.

Role of the countercurrent system in the control of urinary $P_{\mathrm{CO} 2}$. The role of the countercurrent system in the formation of the high urinary $\mathrm{PCO}_{2}$ had been considered previously by Pak Poy and Wrong (13). Based on the observation that patients with renal tubular acidosis often had impaired ability to concentrate the urine, they argued that the principal reason that patients with renal tubular acidosis could not elevate the urinary $\mathrm{PcO}$ with bicarbonate loading was due to their inability to create a gradient for $\mathrm{CO}_{2}$ due to their lack of concentrating ability. Rector $(10,36,37)$ also underscored the importance of the countercurrent system to determine urinary $\mathrm{PCO}_{2}$ levels. He based his reasoning on the fact that the disequilibrium $\mathrm{pH}$ of the distal tubule was reduced by only $0.85 \mathrm{pH}$ units. He concluded that lower disequilibrium $\mathrm{pH}$ values of $1.5-2.0 \mathrm{pH}$ units would be required to generate the observed urinary $\mathrm{CO}_{2}$ tensions. However, it must be pointed out that measurements were made in the distal tubule and not in the collecting duct where the required magnitude for disequilibrium $\mathrm{pH}$ might have been achieved.

Two of our patients (G. B. and R. M.) had a normal concentrating capacity ( $U_{\max } 875$ ), yet were unable to elevate the urine $\mathrm{PCO}_{2}$ and establish a U-B $\mathrm{PCO}_{2}$ gradient after bicarbonate administration. This fact is more conclusive evidence demonstrating that a defect in the ability to concentrate the urine is not responsible for 
the inability of patients with type I (distal) renal tubular acidosis to elevate the urinary $\mathrm{PCO}_{2}$ after bicarbonate administration.

A recent study by Uhlich, Baldamus, and Ullrich (34) clarifies the mechanisms leading to the development of an elevated $\mathrm{PCO}_{2}$ in alkaline urine. These investigators measured bicarbonate, $\mathrm{PcO}_{2}$, and $\mathrm{pH}$ in the renal artery, vasa recta, and collecting duct samples during saline infusion, bicarbonate infusion, and after the administration of carbonic anhydrase or Diamox. They demonstrated that during bicarbonate infusion the vasa recta $\mathrm{PCO}_{2}$ exceeds that in the renal arterial by only $10 \mathrm{~mm}$ $\mathrm{Hg}$. Further, the equilibrium value for $\mathrm{PCO}_{2}$ in the collecting duct was $30 \mathrm{~mm} \mathrm{Hg}$ higher than the vasa recta value. During carbonic anhydrase infusion there was no significant difference between the renal artery, vasa recta, or collecting duct $\mathrm{PCO}_{2}$ tensions. These results are strongly suggestive that the major portions of the rise in urinary $\mathrm{PCO}_{2}$ is due to secretion of $\mathrm{H}^{+}$into the distal tubule and collecting duct with delayed dehydration causing the formation of $\mathrm{CO}_{2}$ in portions of the collecting system which are relatively impermeable to $\mathrm{CO}_{2}$. Furthermore, the elevation of papillary $\mathrm{Pco}_{2}$ to a value greater than arterial $\mathrm{PCO}_{2}$ during bicarbonate infusion is most likely the result of medullary trapping of $\mathrm{CO}_{2}$ formed by secretion of $\mathrm{H}^{+}$into the distal tubule and delivery to the collecting duct and papilla as a result of delayed dehydration.

From the foregoing analysis it can be appreciated that the U-B $\mathrm{PCO}_{2}$ gradient in alkaline urine is primarily the result of secretions of $\mathrm{H}^{+}$into the distal tubule and collecting duct with subsequent delayed dehydration. It follows then, that the U-B $\mathrm{Pco}_{2}$ gradient during $\mathrm{HCO}_{3}$ loading can serve as a qualitative index of the capacity of the distal nephron to secrete $\mathrm{H}^{+}$hydrogen ions.

Interpretation of $\mathrm{PCO}_{2}$ levels in alkaline urine in renal tubular acidosis

The evidence reviewed above is strongly suggestive that the ability to elevate the urine Pcos after bicarbonate administration depends on the ability to secrete hydrogen ions into the distal nephron. Therefore the capacity to raise the urinary $\mathrm{Pco}_{2}$ and establish significant U-B $\mathrm{PCO}_{2}$ gradients is a qualitative measurement of the hydrogen ion-secretory capacity of the distal nephron. The inability of patients with type I (distal) renal tubular acidosis to elevate their urinary $\mathrm{PCO}_{2}$ during bicarbonate loading is indicative that there is an impaired capacity to secrete hydrogen ions in the distal nephron. Our study was designed to obtain the urine $\mathrm{pH}$ as great as or greater than blood $\mathrm{pH}$ to insure that no gradient between blood and urine would be present in the distal nephron. As there was no significant U-B $\mathrm{Pco}_{2}$ gradient in the patients with type I (distal) renal tubular acido- sis, we can assume that delayed dehydration did not occur and that the collecting duct and final urine $\mathrm{pH}$ were similar. The failure of hydrogen ion secretion to occur under these circumstances implies a marked diminution or even a complete absence of hydrogen ion secretory capacity in the distal nephron rather than an inability to secrete hydrogen ions against a gradient. For these same reasons, the continued secretion of hydrogen ions but the inability to obtain a low tubular fluid urine $\mathrm{pH}$ because of hydrogen ion back diffusion down a concentration gradient can be excluded as the mechanism for distal renal tubular acidosis (if this were the case hydrogen ion secretion and delayed dehydration should have been demonstrable).

The hypothesis that distal renal tubular acidosis is due to localized dysfunction of the cells in the distal nephron (presumably in the collecting duct) is consistent with most of the available information about the disease. The bicarbonate reabsorptive capacity $\left(\mathrm{T}_{\mathrm{m}}\right.$ $\mathrm{HCO}_{s}$ ) in distal renal tubular acidosis is usually normal $(3,23,25)$. This is compatible with our hypothesis in view of the limited secretory capacity of the collecting duct in relation to the other segments of the nephron (10). It is unlikely, therefore, that even in the event of a complete absence of hydrogen ion secretion throughout the collecting duct, that a significant decrease in the total hydrogen ion-secretory capacity could be detected. In addition, patients with distal renal tubular acidosis are often moderately sodium and potassium depleted $(39,40)$, both of which augment proximal tubular bicarbonate reabsorption, and slight augmentation of proximal tubular bicarbonate reabsorptive capacity could easily mask decreased or absent bicarbonate reabsorption in the collecting duct.

The ability of patients with type I (distal) renal tubular acidosis to increase the excretion of titratable acid after phosphate infusion is well established $(23,25$, 41). This finding is compatible with the absence of hydrogen ion-secretory function in the collecting duct. Available evidence suggests that hydrogen ion secretion in the proximal and distal tubules is gradient limited and operates below capacity under normal conditions $(38,42,43)$. Therefore increasing the phosphate load to these nephron segments should progressively augment the titratable acid excretion. In addition, if man can lower the distal tubular fluid $\mathrm{pH}$ to $6.0-6.2$ as can the rat $(38,42)$, then phosphate would be titrated to $75 \%$ of its capacity by the end of the distal tubule. Therefore the collecting duct hydrogen-ion secretion would not be expected to contribute greatly to the phosphate titration.

Bicarbonate excretion increases directly as a function of the urine flow rate (23). This was interpreted as evidence of a gradient-limited defect. In the absence of 
hydrogen ion secretion in the collecting duct, the only distal hydrogen ion-secretory cells in this situation would be the cells of the distal tubule. As these cells are thought to be primarily gradient limited with the maximum gradient being $6.0-6.2(38,42,43)$, the absence of collecting duct hydrogen ion-secretory function would, in effect, mimic a "gradient-limited" type of defect in this respect.

An additional finding in patients with type I (distal) renal tubular acidosis which requires consideration is the observation by Reynolds (23) that phosphate infusion causes a marked increase in the urinary $\mathrm{PCO}_{2}$ in patients who did not raise the urinary $\mathrm{PCO}_{2}$ during bicarbonate infusion. Phosphate plays a central role in the production of elevated urinary $\mathrm{PCO}_{2}$ tensions as it is the principal urinary buffer under normal conditions. The urinary buffer plays two roles in raising the urinary $\mathrm{PCO}_{2}$. (a) It supplies the great magnitude of the hydrogen ions when the $\mathrm{pH}$ rises as a result of delayed dehydration of $\mathrm{H}_{2} \mathrm{CO}_{3}(8)$. (b) It is largely responsible for delaying the dehydration of carbonic acid in the distal nephron (31).

In normal subjects and patients with type I (distal) renal tubular acidosis, the normal base-line buffer excretion is similar $(18)^{3}$ and adequate to accomplish both roles. Why pharmacological quantities of phosphate can elevate the urinary $\mathrm{Pco}_{2}$ in some patients with type I (distal) renal tubular acidosis when normal excretory rate cannot is speculative, but several possibilities can be entertained. One of the more plausible explanations would be the capacity of very high phosphate concentrations to markedly delay the dehydration of carbonic acid formed in the distal tubule $(31,44)$. Rector, Portwood, and Seldin (44) showed that very low buffer concentrations are adequate to delay the dehydration of $\mathrm{H}_{2} \mathrm{CO}_{3}$ enough to significantly elevate the urinary $\mathrm{PCO}_{2}$ in normal subjects. However, if collecting duct secretion is absent in patients with type I (distal) renal tubular acidosis, a disequilibrium $\mathrm{pH}$ formed in the distal tubule might be dissipated before reaching the renal pelvis at normal rates of phosphate excretion. By contrast, in the presence of very high rates of buffer excretion, the dehydration of $\mathrm{H}_{2} \mathrm{CO}_{3}$ formed in the distal tubule might be delayed to the extent that $\mathrm{CO}_{2}$ formation takes place in the renal pelvis.

The second possible explanation for the phosphate effect is that phosphate infusion should increase the nonreabsorbable anion load delivered to the distal nephron. As the infusion of nonreabsorbable anions increase the potential difference in the distal tubule (45), hydrogen ion secretion down a favorable electrical gradient might be induced by phosphate infusion. Finally, phosphate

\footnotetext{
${ }^{3}$ Halperin, M. L., M. B. Goldstein, A. Haig, M. D. Johnson, and B. J. Stinebaugh. Unpublished observations.
}

infusion might elevate the medullary $\mathrm{PcO}_{2}$. This could be accomplished by back titration of the phosphate with proton release during passage through the descending loop of Henle if the $\mathrm{pH}$, indeed, rises in this region as suspected (46). The protons released should combine with bicarbonate to form carbonic acid and ultimately $\mathrm{CO}_{2}$ which would be delivered to the medulla and trapped by the countercurrent system. Uhlich, Baldamus, and Ullrich have shown that medullary $\mathrm{PCO}_{2}$ rises markedly after the administration of acetazolamide, presumably as a result of delayed dehydration of carbonic acid in the proximal tubule with subsequent delivery of $\mathrm{CO}_{2}$ to the medullary region (34). A similar effect could result from increased delivery of $\mathrm{CO}_{2}$ to the medulla as a result of phosphate infusion. Our proposal of diminished or absent secretion of hydrogen ion by the collecting duct is compatible with all these possible mechanisms by which phosphate infusion may elevate the urinary $\mathrm{PCO}_{2}$ in patients with distal renal tubular acidosis.

\section{ACKNOWLEDGMENTS}

The authors are very grateful to Mr. W. Chisnell, Mr. R. Feldman, Mr. D. von Laethem, Mr. M. O'Sullivan, and Mrs. I. Shustik for their expert technical assistance. We wish to acknowledge the kind cooperation of Doctors W. Balfe, H. P. Higgins, and D. R. Wilson for allowing us to include their patients in this study.

\section{REFERENCES}

1. Halperin, M. L., A. Haig, M. D. Johnson, and B. J. Stinebaugh. 1972. Mechanism of type I (distal) renal tubular acidosis (RTAd) as revealed by urinary $\mathrm{PCO}_{2}$ levels. Clin. Res. 21 : 957.

2. Halperin, M. L., A. Haig, M. D. Johnson, and B. J. Stinebaugh. 1973. Clin. Res. 22: 689.

3. Seldin, D. W., and J. D. Wilson. 1972. Renal tubular acidosis. In Inherited Basis of Metabolic Disease. J. B. Stanbury, J. B. Wyngaarden, and D. S. Fredrickson, editors. McGraw Hill Book Company, New York. 3rd edition. 1548.

4. Morris, R. C., Jr. 1969. Renal tubular acidosis: mechanisms, classification and implications. N. Engl. J. Med. 281 : 1405.

5. Rodriguez-Soriano, J., and C. M. Edelmann, Jr. 1969. Renal tubular acidosis. Annu. Rev. Med. 20: 363.

6. Morris, R. C., Jr., A. Sebastian, and E. McSherry. 1972. Renal acidosis. Kidney Int. 1: 322.

7. Wrong, O., and H. E. F. Davies. 1959. The excretion of acid in renal disease. Q. J. Med. 23: 259.

8. Rector, F. C., Jr., N. W. Carter, and D. W. Seldin. 1965. The mechanism of bicarbonate reabsorption in the proximal and distal tubules of the kidney. J. Clin. Invest. $44: 278$.

9. Rector, F. C., Jr., D. W. Seldin, A. D. Roberts, Jr., and J. S. Smith. 1960. The role of plasma $\mathrm{CO}_{2}$ tension carbonic anhydrase activity in the renal reabsorption of bicarbonate. J. Clin. Invest. 39: 1706.

10. Rector, F. C., Jr. 1964. Micropuncture studies on the mechanism of urine acidification. In Renal Metabolism and Epidemiology of Some Renal Diseases. J. Metcoff, 
editor. The Maple Press Company of York, York, Pa. 1 st edition. 9.

11. Häussler, G. 1958. Zur technik und spezifität des histochemischen carbonanhydrasenachweises in modellversuch und in gewegsschnitten von rattentieren. Histochemie. $1: 29$.

12. Maren, T. J. 1967. Carbonic anhydrase: chemistry, physiology and inhibition. Physiol. Rev. 47: 595.

13. Pak Poy, R. K., and O. Wrong. 1960. The urinary $\mathrm{PCO}_{2}$ in renal disease. Clin. Sci. (Oxf.). 19: 631.

14. Fillastre, J. P., R. Ardaillou, and G. Richet. 1969. pH et $\mathrm{P} \mathrm{CO}_{2}$ urinaires en réponse à une surcharge alcaline au cours de l'insufflsance rénale chronique. Nephron. 6: 91.

15. Zall, D. M., D. Fisher, and M. Q. Garner. 1956. Photometric determination of chloride in water. Anal. Chem. 28: 1665 .

16. Skeggs, L. T., Jr. 1960. An automatic method for the determination of carbon dioxide in blood plasma. $\mathrm{Am}$. J. Clin. Pathol. 33 : 181.

17. Fiske, C. H., and Y. Subbarow. 1925. The colorimetric determination of phosphorus. J. Biol. Chem. 66: 375.

18. Portwood, R. M., D. W. Seldin, F. C. Rector, Jr., and R. Cade. 1959. The relation of urinary $\mathrm{CO}_{2}$ tension to bicarbonate excretion. J. Clin. Invest. 38: 770.

19. Hills, A. G., and E. L. Reid. 1970. $\mathrm{PCO}_{2}$ and $\mathrm{PNH}_{3}$ in mammalian kidney and urinary tract related to urine $\mathrm{pH}$ and flow. Am. J. Physiol. 219: 423.

20. Sebastian, A., E. McSherry, and R. C. Morris, Jr. 1971. On the mechanism of renal potassium wasting in renal tubular acidosis associated with Fanconi syndrome (Type II RTA). J. Clin. Invest. 50: 231.

21. McSherry, E., A. Sebastian, and R. C. Morris, Jr. 1972. Renal tubular acidosis in infants: the several kinds, including bicarbonate-wasting, classical renal tubular acidosis. J. Clin. Invest. 51: 499.

22. György, A. Z., and K. D. G. Edwards. 1968. Renal tubular acidosis. A family with an autosomal dominant genetic defect in renal hydrogen ion transport, with proximal tubular and collecting duct dysfunction and increased metabolism of citrate and ammonia. Am. J. Med. $45: 43$.

23. Reynolds, T. B. 1958. Observations on the pathogenesis of renal tubular acidosis. Am. J. Med. 25: 503.

24. Kurtzman, N. A., M. G. White, and P. W. Rogers. 1971. Aldosterone deficiency and renal bicarbonate reabsorption. J. Lab. Clin. Med. 77 : 931.

25. Smith, L. H., Jr., and G. E. Schreiner. 1954. Studies on renal hyperchloremic acidosis. J. Lab. Clin. Med. $43: 347$.

26. Mainzer, F., and M. Bruhn. 1931. Über löslichkeit, dissoziation und spannung der kohlensäure im harn. Biochem. Z. 230 : 395.

27. Pitts, R. F., and W. D. Lotspeich. 1946. Bicarbonate and the renal regulation of acid base balance. $A m$. J. Physiol. 147 : 138.

28. Pitts, R. F., W. D. Lotspeich, J. L. Ayer, and W. A. Schiess. 1948. The renal regulation of acid-base balance in man. III. The reabsorption and excretion of bicarbonate. J. Clin. Invest. 27 : 48.

29. Ryberg, C. 1948. Some investigations on the carbon dioxide tension of the urine in man. Acta Physiol. Scand. 15: 123.

30. Kennedy, T. J., Jr., J. Orloff, and R. W. Berliner. 1952. Significance of carbon dioxide tension in urine. Am. J. Physiol. 169 : 596.

31. Kennedy, T. J., Jr., M. Eden, and R. W. Berliner. 1957. Interpretation of urine $\mathrm{CO}_{2}$ tension. Fed. Proc. 16: 72.

32. Reid, E. L., and A. G. Hills. 1965. Diffusion of carbon dioxide out of the distal nephron in man during antidiuresis. Clin. Sci. (Oxf.). 28: 15.

33. Reid, E. L., and A. G. Hills. 1969. The effect of delayed dehydration of carbonic acid on renal bicarbonate clearance and its significance for acid-base balance. Clin. Sci. (Oxf.). 37: 381.

34. Uhlich, E., C. A. Baldamus, and K. J. Ullrich. 1968. Verhalten von $\mathrm{CO}_{2}$-Druck und bicarbonat im gegenstromsystem des nierenmarks. Pfuegers Arch. Eur. J. Physiol: $303: 31$.

35. Ochwadt, B. K., and R. F. Pitts. 1956. Effects of intravenous infusion of carbonic anhydrase on carbon dioxide tension of alkaline urine. Am. J. Physiol. 185: 426.

36. Rector, F. C., Jr., N. W. Carter, and D. W. Seldin. 1966. The renal transport of hydrogen ion. Proc. Int. Congr. Nephrol. $1: 76$.

37. Rector, F. C., Jr. 1971. Renal secretion of hydrogen. In The Kidney. III. Morphology, Biochemistry and Physiology. C. Rouiller and A. F. Muller, editors. Academic Press, Inc., New York. 209.

38. Vieira, F. L., and G. Malnic. 1968. Hydrogen ion secretion by rat renal cortical tubules as studied by an antimony microelectrode. Am. J. Physiol. 214: 710.

39. Gill, J. R., Jr., N. H. Bell, and F. C. Bartter. 1967. Impaired conservation of sodium and potassium in renal tubular acidosis and its correction by buffer anions. Clin. Sci. (Oxf.). 33: 577.

40. Fleishman, S. J., B. Senior, and M. M. Suzman. 1959. Renal tubular acidosis-the role of defective renal tubular sodium reabsorption and secondary hyperaldosteronism in its pathogenesis. Arch. Intern. Med. 104: 613.

41. Morris, R. C., C. F. Piel, and E. Audioun. 1965. Renal tubular acidosis: effects of sodium phosphate and sulfate on renal acidification in two patients with renal tubular acidosis. Pediatrics. 36: 899.

42. Malnic, G., M. de Mello Aires, and G. Giebisch. 1972. Micropuncture study of renal tubular hydrogen ion transport in the rat. Am. J. Physiol. 222: 147.

43. Malnic, G., and G. Giebisch. 1972. Mechanism of renal hydrogen ion secretion. Kidney Int. 1: 280.

44. Rector, F. C., Jr., R. M. Portwood, and D. W. Seldin. 1959. Examination of the mixing hypothesis as an explanation for elevated urinary $\mathrm{CO}_{2}$ tensions. $\mathrm{Am}$. J. Physiol. 197 : 861 .

45. Clapp, J. R., F. C. Rector, Jr., and D. W. Seldin. 1962. Effect of unreabsorbed anions on proximal and distal transtubular potentials in rats. Am. J. Physiol. 202: 781 .

46. Gottschalk, C. W., W. E. Lassiter, and M. Mylle. 1960. Localization of urine acidification in the mammalian kidney. Am. J. Physiol. 198: 581. 